\title{
STRATEGI PEMENUHAN KEBUTUHAN POKOK RUMAH TANGGA DI PADANG UTARA (STUDI: RUMAH TANGGA TUKANG BECAK DAYUNG DI KECAMATAN PADANG UTARA)
}

\author{
Fefrori Putri' ${ }^{1}$, Yurni Suasti2 \\ Program Studi Peddikan Geografi \\ Fakultas Ilmu Sosial Universitas Negeri Padang \\ Email: fefroriputri18@gmail.com
}

\begin{abstract}
ABSTRAK
Penelitian ini bertujuan untuk mendeskripsikan strategi yang dilakukan Tukang Becak Dayung dalam pemenuhan kebutuhan pokok kecamatan Padang Utara. Penelitian ini adalah penelitian deskriptif kualitatif yang dilakukan di Padang Utara, Kota Padang. Subjek penelitian ini yaitu penarik Becak Dayung. Sementara teknik Pengumpulan Data dengan wawancara dan studi dokumentasi. Alat pengumpul data utamanya peneliti dengan dibantu pedoman wawancara dan catatan lapangan. Kemudian uji keabsahan data dilakukan melalui teknik triangulasi sumber. Data yang diperoleh selama penelitian berlangsung dianalisis dengan cara reduksi data, display data/penyajian data, dan mengambil kesimpulan lalu diverifikasi. Penelitian ini menemukan bahwa strategi yang dilakukan tukang becak dayung dalam memenuhi kebutuhan pokok rumah tangga menerapkan strategi aktif, strategi pasif dan strategi jaringan.
\end{abstract}

Kata Kunci; Strategi, kebutuhan, becak dayung.

\begin{abstract}
This study aims to describe the strategies carried out by Rowing Pedicablers in meeting the basic needs of Padang Utara sub-district. This research is a qualitative descriptive study conducted in Padang Utara, Padang City. The subject of this research is towing Rowing Rickshaw. While the technique of data collection with interviews and documentation study. The main data collection tool for researchers is assisted by interview guidelines and field notes. Then the data validity test is done through source triangulation techniques. Data obtained during the study took place analyzed by means of data reduction, data display / data presentation, and conclusions and then verified. This study found that the strategies carried out by rowing pedicab drivers in meeting basic household needs applied active strategies, passive strategies and network strategies.
\end{abstract}

Keywords; Strategy, need, rowing rickshaw 


\section{PENDAHULUAN}

Kota Padang merupakan kota yang cukup fenomenal akan berbagai jenis alat transportasi. Mulai dari alat transportasi tradisional sampai alat transportasi modern. Becak dayung merupakan salah satu alat transportasi tradisional di Kota padang, tepatnya di Padang Utara yang masih bertahan hingga saat ini. Ada tiga titik tempat beroperasinya becak dayung di Kota Padang, yakninya Air tawar Timur, Air Tawar Barat, dan Ulak Karang Utara. Sehingga masyarakat bisa dengan mudah mendapatkan jasa transportasi yang diinginkan. Hal ini tentu menunjang untuk kesejahteraan hidup manusia. Menurut UU RI No. 11 tahun 2009 tentang kesejahteraan sosial, "kesejahteraan sosial adalah kondisi terpenuhinya kebutuhan material, spiritual dan sosial warga Negara agar dapat hidup layak dan mampu mengembangkan diri, sehingga dapat melaksanakan fungsi sosialnya. " Sebagai makhluk hidup yang hidup bersama tentunya tidak terlepas dari budaya, lingkungan, waktu serta agama dan pasti memiliki berbagai macam kebutuhan yang harus dipenuhi. Semakin tinggi tingkat kebudayaan seseorang semakin tinggi pula tingkat kebutuhan yang harus dipenuhi.

Menurut (Badan Pusat Statistik,1994) "masyarakat yang sejahtera ditandai dengan masyarakat yang mampu menggunakan sumber pendapatannya untuk memenuhi kebutuhan sehari-hari, antara lain kebutuhan primer, sekunder dan tersier." Kebutuhan primer disini menyangkut kebutuhan pokok tukang becak dayung seperti memenuhi kebutuhan belanja makan sehari-hari, sedangkan kebutuhan sekunder seperti kebutuhan tambahan apabila kebutuhan pokok sudah terpenuhi, begitupun dengan kebutuhan tersier apabila kebutuhan primer dan sekunder telah terpenuhi dengan baik. Untuk memenuhi kebutuhan itu tentunya harus ada pekerjaan yang dapat menhasilkan materi maupun uang dari penghasilan tersebut sedikit banyaknya kebutuhannya terpenuhi. Hakikatnya pemenuhan kebutuhan ini tidak pernah berakhir karena sifat kebutuhan manusia tidak pernah merasa puas.

Pada dasarnya untuk membina kesejahteraan hidup, manusia memerlukan lima macam kebutuhan yang biasa disebut kebutuhan mendasar atau kebutuhan pokok. Kebutuhan pokok tersebut meliputi kebutuhan sandang, pangan, papan, pendidikan dan kesehatan. Disamping itu kondisi keamanan lingkungan merupakan kebutuhan untuk mendukung kehidupan dan keberadaan manusia. Pemenuhan kebutuhan pokok tersebut tergantung pada kemampuan atau kesanggupan seseorang atau kelompok dalam memenuhinya. Selama masih hidup selalu mempunyai kebutuhan untuk mempertahankan kehidupannya dan mengangkat derajat kualitas hidupnya sehari-hari. 
Ditengah maraknya transportasi modern, becak dayung tetap bertahan di Kota Padang, khususnya di Padang Utara sebagai alat transportasi tradisional. Namun, kehidupan para tukang becak dayung yang masih bertahan kini cukup memprihatinkan. Terlebih, seiring perkembangan arus transportasi modern saat ini yang secara otomatis membuat jasa becak dayung jarang digunakan lagi oleh pengguna jasa transportasi. Hal ini akan membuat becak dayung mengalami penurunan pendapatan dan peminatnya. Ini akan berdampak pada pemenuhan kebutuhan pokok rumah tangga becak dayung. Belum lagi ditambah harga kebutuhan pokok yang semakin mahal dan kurang adanya perhatian khusus dari Pemerintah Kota Padang. Yang kalau dilihat dulunya menjadi 'Primadona Transportasi' yang selalu dicari, namun kini tidak lebih hanya sekedar 'ada atau tidaknya mereka tidak menjadi masalah' dan dari dinas kota padang tidak ada lagi data yang akurat mengenai jumlah tukang becak dayung yang ada hingga saat ini.

Dalam hal ini peneliti ingin melihat bagaimana stategi bertahan hidup tukang becak dayung dalam memenuhi kebutuhan pokok yang tertuang dalam sebuah judul penelitian "Strategi Pemenuhan Kebutuhan Pokok Rumah Tangga di Padang Utara (Studi Rumah Tangga Tukang Becak Dayung di Kecamatan Padang Utara)"
Tulisan ini bertujuan untuk mendeskripsikan strategi pemenuhan kebutuhan pokok rumah tangga Tukang Becak Dayung di Kecamatan Padang Utara, tujuan lebih rinci adalah : untuk mengetahui sejauh mana upaya strategi yang dilakukan Tukang Becak Dayung dalam pemenuhan kebutuhan pokok Kecamatan Padang Utara.

Suharto (2002) menyatakan bahwa definisi dari strategi bertahan hidup (coping strategis) adalah kemampuan seseorang dalam menerapkan seperangkat cara untuk mengatasi berbagai permasalahan yang melingkupi kehidupannya. Dalam konteks keluarga miskin, strategi penanganan masalah ini pada dasarnya merupakan kemampuan segenap anggota keluarga dalam mengelola segenap asset yang dimilikinya. Bisa juga disamakan dengan kapabilitas keluarga miskin dalam menanggapi goncangan dan tekanan (Shock and Stress).

Selanjutnya Suharto (2002) dalam Zainal Abidin juga menyatakan strategi bertahan hidup (coping strategies) dalam mengatasi goncangan dan tekanan ekonomi dapat dilakukan dengan berbagai cara. Cara-cara tersebut dapat dikelompokkan menjadi 3 kategori yaitu: (a) Strategi aktif, yaitu strategi yang mengoptimalkan segala potensi keluarga untuk (misalnya melakukan aktivitasnya sendiri, memperpanjang jam kerja, memanfaatkan sumber atau tanaman liar dilingkungan sekitar dan 
sebagainya). (b) Strategi pasif, yaitu mengurangi pengeluaran keluarga (misalnya pengeluaran sandang, pangan, pendidikan dan sebagainya). (c) Strategi jaringan, misalnya menjalin relasi, baik formal maupun informal dengan lingkungan sosialnya, dan lingkungan kelembagaan (misalnya : meminjam uang tetangga, mengutang diwarung, memanfaatkan program kemiskinan, mimanjam uang ke rentenir atau bank dan sebagainya.

\section{METODE PENELITIAN}

Penelitian ini merupakan penelitian deskriptif kualitatif. Dalam penelitian ini maka lokasi penelitian yaitu di Kecamatan Padang Utara, Kota Padang. Penelitian ini dilaksanakan dari bulan Agustus sampai Oktober 2017.

Dalam penelitian kualitatif, pengumpulan data dilakukan pada natural setting (kondisi yang alamiah), sumber data primer, dan pengumpulan data lebih banyak pada obeservasi berperan serta (participant observation), wawancara mendalam (in depth interview) dan dokumentasi (Sugiyono : 2005). Dalam penelitian ini penelitian melakukan pengumpulan data dengan cara : (a) Observasi, yaitu peneliti langsung terjun kelapangan untuk mengamati permasalahan yang diteliti. (b) Wawancara, yaitu penulis langsung berhadapan dengan pihak-pihak yang dimintai keterangan sesuai dengan objek yang akan diteliti untuk memperoleh data internal yang bersangkutan. (c) Dokumentasi, yaitu untuk memperkuat dan memperejelas data penelitian maka peneliti juga mengambil beberapa dokumentasi. (d) Triangulasi, diartikan sebagai teknik pengumpulan data yang bersifat menggabungkan dari berbagai teknik pengumpulan data dan sumber data yang telah ada. Bila peneliti melakukan pengumpulan data dengan triangulasi, maka sebenarnya peneliti mengumpulkan data yang sekaligus menguji kredibilitas data, yaitu mengecek kredibilitas data dengan berbagai teknik pengumpulan data dan berbagai sumber data.

\section{HASIL DAN PEMBAHASAN}

Pendapatan dan pengeluaran Tukang Becak Dayung di Padang Utara

Dalam penelitian ini penulis mendapatkan data keseluruhan tukang becak dayung di Padang Utara berjumlah 34 orang. Berikut merupakan data informan tukang becak dayung di Kecamatan Padang Utara. 
Tabel 1. Data primer berdasarkan pendidikan, pendapatan dan pengeluaran

\begin{tabular}{lllll}
\hline No. & \multicolumn{1}{c}{ Nama } & Pendidikan & \multicolumn{1}{c}{ Pendapatan/hari } & \multicolumn{1}{c}{ Pengeluaran/hari } \\
\hline 1 & Siral & SMA & Rp. 12.000 - Rp. 30.000 & Rp. 26.000 - Rp. 50.000 \\
\hline 2 & Wondo & SMA & Rp. $25.000-$ Rp. 50.000 & Rp. $30.000-$ RP. 40.000 \\
\hline 3 & Ajo E & SD & Rp. 25.000 - RP. 30.000 & Rp. 25.000 - RP. 50.000 \\
\hline 4 & Udin S & SMP & Rp. 20.000 - RP. 45.000 & RP. 35.000 - RP. 60.000 \\
\hline 5 & Eri & SD & Rp. $15.000-$ RP. 30.000 & Rp. 15.000 - RP. 50.000 \\
\hline 6 & Mus & SD & Rp. $30.000-$ RP. 50.000 & Rp. 20.000 - RP. 50.000 \\
\hline 7 & Yon & SD & Rp. 0 - RP. 30.000 & Rp. 20.000 - RP. 30.000 \\
\hline 8 & Andre & SD & Rp. $50.000-$ RP. 60.000 & Rp. 45.000 - RP. 50.000. \\
\hline
\end{tabular}

Sumber: Data Primer

Berdasarkan tabel diatas dapat diperoleh informasi bahwa tukang becak dayung memiliki pendapatan rata-rata yaitu Rp. 30.000,-/hari. Sedangkan rata-rata pengeluaran tukang becak dayung lebih besar dibandingkan pendapatan yang mereka terima dalam artian lain untuk kebutuhan pokok mereka tidak terpenuhi. Selain itu pada umumnya tingkat pendidikan para tukang becak dayung di Kota Padang hanya tamatan SD. Hal ini menandakan tidak adanya keterampilan lain yang dimiliki para tukang becak dayung untuk beralih kepada pekerjaan yang layak dalam memenuhi kebutuhan hidupnya sehari-hari. Pendapatan tersebut bisa saja menurun jika penumpang sepi dan terkadang ada diantara penumpang yang enggan membayar yang disepakati atau bisa bertambah jika mendapatkan penumpang yang bermurah hati membayar lebih. Pendapatan yang kecil dan tidak menentu membuat subjek tidak mampu memenuhi semua kebutuhan keluarga karena untuk memenuhi semua kebutuhan keluarganya. Jumlah tanggungan tukang becak dayung berbeda-beda, seperti Pak Andre dan Pak Udin S yang memiliki tanggungan tiga orang, Pak Eri memiliki dua orang tanggungan, Pak Feri dan Pak Ajo memiliki satu orang tanggungan, Pak Siral dan Pak Wondo belum ada tanggungan dikarenakan belum memiliki isteri, dan terakhir Pak Mus tidak memiliki tanggungan karena semua anaknya telah berkeluarga diperantauan dan isterinya meninggal dunia, sehingga ia hidup sendiri lalu menjalani rutinitas sebagai penarik becak untuk memenuhi kebutuhan sehari-hari. Menurut Rachbini (dalam Suasti dan Fajri,2018), ciri-ciri dari sektor informal tersebut adalah upah atau gaji yang tidak tetap, rendah serta tidak cukup memadai. 
Strategi Pemenuhan Kebutuhan Pokok Tukang Becak Dayung di Padang Utara.

Strategi bertahan hidup

(coping strategies) atau strategi pemenuhan kebutuhan pokok rumahtangga tukang becak dayung di Padang Utara dalam mengatasi goncangan dan tekanan ekonomi dapat dilakukan dengan berbagai cara. Cara-cara tersebut dapat dikelompokkan menjadi 3 kategori yaitu:

\section{a. Strategi aktif}

Yaitu strategi yang mengoptimalkan segala potensi keluarga untuk (misalnya melakukan aktivitasnya sendiri, memperpanjang jam kerja, memanfaatkan sumber atau tanaman liar dilingkungan sekitar dan sebagainya).

\section{b. Strategi pasif}

Yaitu

mengurangi

pengeluaran keluarga (misalnya

pengeluaran sandang, pangan, pendidikan dan sebagainya).

\section{c. Strategi jaringan}

Misalnya menjalin relasi, baik formal maupun informal dengan lingkungan sosialnya, dan lingkungan kelembagaan (misalnya : meminjam uang tetangga, mengutang diwarung, memanfaatkan program kemiskinan, mimanjam uang ke rentenir atau bank dan sebagainya.

Berdasarkan pembahasan di atas dapat dijelaskan, bahwa terdapat perbedaan penerapan strategi dalam pemenuhan kebutuhan pokok tukang becak dayung di Kecamatan Padang Utara. Untuk lebih jelasnya dapat dilihat pada tabel sebagai berikut:

Tabel 2. Strategi Pemenuhan Kebutuhan Pokok Tukang Becak Dayung di Padang Utara

\begin{tabular}{|c|c|c|c|c|}
\hline No. & Nama & Strategi Aktif & Strategi Pasif & Stra \\
\hline 1 & (30 th) & $\begin{array}{ll}\text { - } & \begin{array}{l}\text { Pergi ikut-ikutan } \\
\text { kerja bersama } \\
\text { teman. }\end{array} \\
\text { - } & \text { Berjualan makanan } \\
& \text { ringan didekat SD } \\
\text { - } & \text { Berjualan bensin } \\
\text { - } & \text { Mengambil start } \\
& \text { awal dalam } \\
& \text { menarik becak. }\end{array}$ & $\begin{array}{l}\text { - } \text { Makan seadanya. } \\
\text { - Lebih } \\
\text { mengedepankan } \\
\text { kebutuhan makan } \\
\text { sehari-hari } \\
\text { dibandingkan } \\
\text { kebutuhan yang } \\
\text { lainnya. }\end{array}$ & $\begin{array}{l}\text { - } \text { Menjalin } \\
\text { silahturahmi } \\
\text { dengan pengguna } \\
\text { becak. } \\
\text { - Memberikan nomor } \\
\text { handphone pada } \\
\text { pengguna becak, } \\
\text { sehingga } \\
\text { memudahkan } \\
\text { memesan becak. }\end{array}$ \\
\hline 2 & $\begin{array}{l}\text { Pak Mus } \\
\text { (57 th) }\end{array}$ & $\begin{array}{ll}\text { - } & \text { Kadang-kadang } \\
\text { pergi melaut } \\
\text { - } \\
\text { Melakukan } \\
\text { pekerjaan } \\
\text { sampingan sebagai } \\
\text { jasa angkat barang }\end{array}$ & \begin{tabular}{ll} 
- & \multicolumn{2}{l}{ Makan seadanya } \\
- & Terima berapa \\
& dapat $\quad$ hasil \\
& pendapatan. \\
- & Lebih \\
& mengedepankan
\end{tabular} & $\begin{array}{ll}\text { - } & \text { Menjalin } \\
\text { silahturahmi } \\
\text { dengan pengguna } \\
\text { becak. } \\
\text { - Memberikan nomor } \\
\text { handphone pada }\end{array}$ \\
\hline
\end{tabular}




\begin{tabular}{|c|c|c|c|c|}
\hline & & $\begin{array}{l}\text { didekat toko, jasa } \\
\text { membersihkan } \\
\text { pekarangan rumah, } \\
\text { kebun, dan taman } \\
\text { milik orang lain, } \\
\text { jasa pindah rumah } \\
\text { kost bagi } \\
\text { mahasiswa sekitar } \\
\text { Air Tawar. }\end{array}$ & $\begin{array}{l}\text { kebutuhan makan } \\
\text { sehari-hari } \\
\text { dibandingkan } \\
\text { kebutuhan yang } \\
\text { lainnya. }\end{array}$ & $\begin{array}{l}\text { pengguna becak, } \\
\text { sehingga } \\
\text { memudahkan } \\
\text { memesan becak. }\end{array}$ \\
\hline 3 & $\begin{array}{l}\text { Pak Udin } \\
\text { Sampono } \\
\text { (32 th) }\end{array}$ & $\begin{array}{ll}\text { - } & \text { Melakukan } \\
\text { pekerjaan } & \\
\text { sampingan } & \text { sebagai } \\
\text { jasa pindah rumah } \\
\text { kost } & \text { bagi } \\
\text { mahasiswa } & \text { sekitar } \\
\text { Air Tawar. } & \end{array}$ & \begin{tabular}{ll} 
- & \multicolumn{2}{l}{ Makan seadanya } \\
Terima berapa \\
dapat hasil \\
pendapatan. \\
- Lebih \\
mengedepankan \\
kebutuhan makan \\
sehari-hari \\
dibandingkan \\
kebutuhan yang \\
lainnya \\
\end{tabular} & $\begin{array}{l}\text { Memanfaatkan } \\
\text { bantuan sekolah } \\
\text { untuk siswa miskin } \\
\text { sehingga tidak } \\
\text { perlu membayar } \\
\text { spp sekolah anak. }\end{array}$ \\
\hline 4 & $\begin{array}{l}\text { Pak } \\
\text { Wondo } \\
\text { (45 th) }\end{array}$ & \begin{tabular}{lr} 
Melakukan & \\
pekerjaan & \\
sampingan & sebagai \\
tukang & kuli \\
bangunan & di \\
\multicolumn{2}{l}{ sebuah proyek dan } \\
jasa pindah & rumah \\
kost & bagi \\
mahasiswa & sekitar \\
Air Tawar. &
\end{tabular} & $\begin{array}{l}\text { - Makan seadanya. } \\
\text { - Lebih } \\
\text { mengedepankan } \\
\text { kebutuhan makan } \\
\text { sehari-hari } \\
\text { dibandingkan } \\
\text { kebutuhan yang } \\
\text { lainnya. } \\
\text { Pendapatan yang } \\
\text { didapat dicukup- } \\
\text { cukupkan saja. } \\
\end{array}$ & 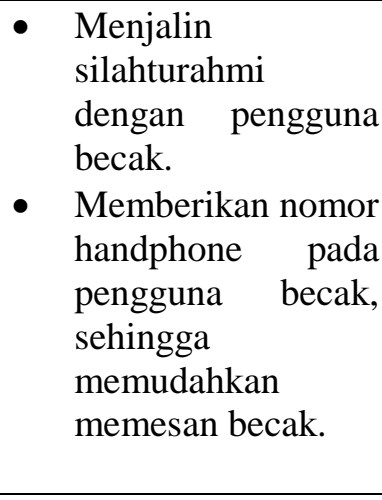 \\
\hline 5 & $\begin{array}{l}\text { Pak Yon } \\
\text { (57 th) }\end{array}$ & 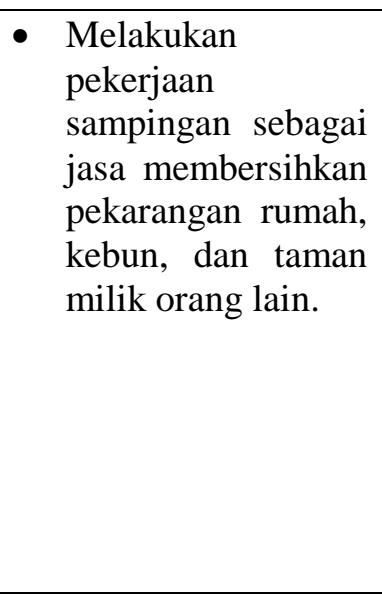 & $\begin{array}{ll}\text { - } & \text { Makan seadanya. } \\
\text { - } & \text { mebih } \\
\text { kebutuhan makan } \\
\text { sehari-hari } \\
\text { dibandingkan } \\
\text { kebutuhan yang } \\
\text { lainnya. } \\
\text { Pendapatan yang } \\
\text { diterima dihemat- } \\
\text { hemat. } \\
\text { Menghemat } \\
\text { belanja }\end{array}$ & 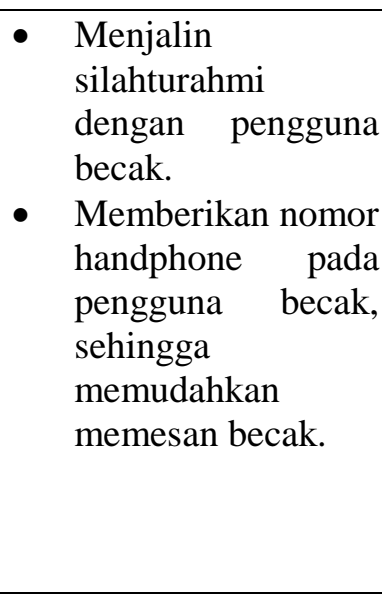 \\
\hline 6 & $\begin{array}{l}\text { Pak Ajo } \\
\text { Enek } \\
\text { (44 th) }\end{array}$ & $\begin{array}{l}\text { - Melakukan } \\
\text { pekerjaan } \\
\text { sampingan sebagai } \\
\text { jasa angkat barang } \\
\text { didekat toko dan }\end{array}$ & $\begin{array}{l}\text { - Makan seadanya } \\
\text { - Pendapatan yang } \\
\text { didapat dicukup- } \\
\text { cukupkan saja. } \\
\text { - Lebih }\end{array}$ & 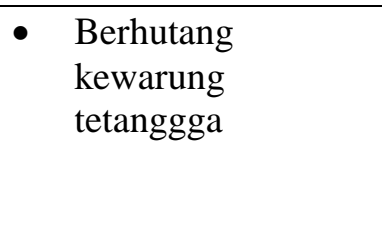 \\
\hline
\end{tabular}




\begin{tabular}{|c|c|c|c|c|c|c|}
\hline & & & $\begin{array}{l}\text { jasa buang sampah } \\
\text { rumah tangga. }\end{array}$ & & $\begin{array}{l}\text { mengedepankan } \\
\text { kebutuhan makan } \\
\text { sehari-hari } \\
\text { dibandingkan } \\
\text { kebutuhan yang } \\
\text { lainnya. }\end{array}$ & \\
\hline 7 & $\begin{array}{l}\text { Pak Eri } \\
\text { (55 th) }\end{array}$ & $\bullet$ & $\begin{array}{l}\text { Melakukan } \\
\text { pekerjaan } \\
\text { sampingan sebagai } \\
\text { tukang } \quad \text { kuli } \\
\text { bangunan } \\
\text { sebuah proyek. }\end{array}$ & & $\begin{array}{l}\text { Makan seadanya } \\
\text { Mengurangi } \\
\text { makan menjadi } \\
\text { dua kali sehari. } \\
\text { Lebih } \\
\text { mengedepankan } \\
\text { kebutuhan makan } \\
\text { sehari-hari } \\
\text { dibandingkan } \\
\text { kebutuhan yang } \\
\text { lainnya. }\end{array}$ & 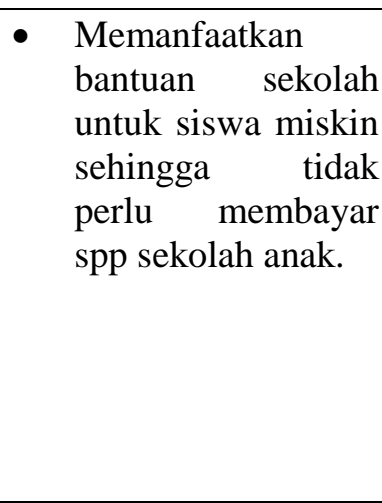 \\
\hline 8 & $\begin{array}{l}\text { Pak } \\
\text { Andre } \\
\text { (45 th) }\end{array}$ & $\bullet$ & $\begin{array}{l}\text { Melakukan } \\
\text { pekerjaan } \\
\text { sampingan sebagai } \\
\text { jasa angkut barang } \\
\text { dan jasa pindah } \\
\text { rumah kost bagi } \\
\text { mahasiswa sekitar } \\
\text { Air Tawar. }\end{array}$ & & $\begin{array}{l}\text { Makan seadanya } \\
\text { Lebih } \\
\text { mengedepankan } \\
\text { kebutuhan makan } \\
\text { sehari-hari } \\
\text { dibandingkan } \\
\text { kebutuhan yang } \\
\text { lainnya. }\end{array}$ & 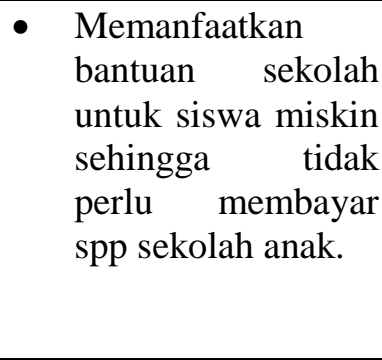 \\
\hline
\end{tabular}

Sumber: Data Primer (2018)

Kendala yang Ditemukan saat Menarik Becak

Berdasarkan hasil wawancara terhadap informan diatas dapat disimpulkan kendala yang ditemukan saat menarik becak diantaranya banyaknya mahasiswa atau masyarakat yang memiliki kendaraan pribadi, bagi mahasiswa dan masyarakat yang jarak kost atau tempat tinggalnya tidak terlalu jauh memilih jalan kaki daripada menggunakan jasa becak untuk menghemat pengeluaran. Penumpang atau pelanggan becak dari masa ke masa mulai sepi sehingga pengguna jasa becak mulai menurun. Kemudian, banyaknya saingan alat transportasi lainnya juga area untuk beroperasi becak dan cuaca yang tidak mendukung seperti hujan memicu jasa becak mulai jarang diminati oleh masyarakat.

\section{KESIMPULAN}

Berdasarkan hasil penelitian dan pengamatan secara langsung yang peneliti lakukan mengenai strategi becak dayung dalam memenuhi kebutuhan hidup maka dapat disimpulkan beberapa hal yaitu berbagai strategi yang ditelah mereka lakukan guna memenuhi kebutuhan pokok tukang becak dayung yakninya strategi aktif, strategi pasif dan strategi jaringan. 
Strategi aktif adalah strategi pemenuhan kebutuhan pokok yang dilakukan keluarga tukang becak dayung dengan mengoptimalkan sumber daya yang mereka miliki untuk menambah pendapatan mereka. Strategi aktif yang dilakukan tukang becak dayung, yaitu mencari pekerjaan sampingan yaitu dengan menjadi pergi ikut-ikutan kerja bersama teman, berjualan makanan ringan didekat $\mathrm{SD}$, berjualan bensin, mengambil start awal dalam menarik becak, kadang-kadang pergi melaut, melakukan pekerjaan sampingan sebagai jasa angkat barang didekat toko, jasa membersihkan pekarangan rumah, kebun, dan taman milik orang lain, dan jasa pindah rumah kost bagi mahasiswa sekitar Air Tawar.

Strategi pasif adalah strategi pemenuhan kebutuhan pokok yang dilakukan dengan menerapkan pola hemat, pendapatan yang kecil menuntut keluarga tukang becak dayung untuk menerapkan budaya hidup hemat seperti makan dengan lauk seadanya, mengurangi makan menjadi dua kali sehari, pendapatan yang diterima dihemat-hemat atau dicukup-cukupkan, menghemat belanja, dan lebih mengedepankan kebutuhan makan sehari-hari dibandingkan kebutuhan yang lainnya Strategi jaringan adalah strategi pemenuhan kebutuhan pokok yang dilakukan dengan cara berhutang kewarung tetangga, menjalin silahturahmi dengan pengguna becak, memberikan nomor handphone pada pengguna becak, sehingga memudahkan memesan becak dan memanfaatkan bantuan sekolah untuk siswa miskin sehingga tidak perlu membayar spp sekolah anak.

\section{DAFTAR PUSTAKA}

Abidin, Zainal. 2014. Strategi Bertahan Hidup Petani Kecil Di Desa Sindetlami Kecamatan Besuk Kabupaten Probolinggo. FIP : Universitas Jember

Fajri, Yurni dkk. 2018. Persebaran Sektor Informal Pedagang Kaki Lima makanan dan minuman di Kota Bukittinggi. E- Journal Universitas Negeri Padang.

Kamaluddin, Rustian. 1987. Ekonomi Transportasi. Jakarta : Ghalia Indonesia.

Sugiyono. 2005. Memahami Penelitian Kualitatif. Jawa Barat: CV. Alfabeta Bandung

Suharto, Edi. 2013. Kemiskinan dan Perlindungan Sosial di Indonesia. Bandung : Alfabeta.

Undang-undang No. 11 Tahun 2009 tentang kesejahteraan sosial. 